\title{
KGF Is Delivered to Inflammatory and Induces the Epithelial Hyperplasia in Trinitrobenzene Sulfonic Acid-Induced Ulcerative Colitis Rats
}

This article was published in the following Dove Press journal:

Drug Design, Development and Therapy

\section{Kai Jia* \\ Yan Wang* \\ Xin Tong \\ Rong Wang}

Department of Nutrition, Beijing ChaoYang Hospital, Capital Medical University, Beijing, People's Republic of China

*These authors contributed equally to this work
Correspondence: Kai Jia

Department of Nutrition, Beijing Chao-

Yang Hospital, No. 8 Gongti South Road,

Chaoyang District, Beijing I00020,

People's Republic of China

$\mathrm{Tel}+86-85231275$

Fax +86-10-839|I276

Email kaijiamyemail@sina.com
Introduction: KGF-modified MSCs can promote the repair of spinal cord injury and pulmonary fibrosis injury in rats. However, the effect of KGF-modified MSCs on UC rats is unclear. We aimed to explore the therapeutic effect and possible mechanism of KGF genemodified MSCs on trinitrobenzene sulfonic acid (TNBS)-induced UC rats.

Methods: The lentivirus-mediated KGF gene was introduced into bone marrow MSCs of male rats. Female SD rats were induced to establish a UC model by TNBS. Untreated MSCs, MSCs carrying empty vectors (MSCs-vec) or MSCs carrying KGF gene (MSCs-KGF) were transplanted into UC rats by tail vein injection.

Results: Significantly high expression of KGF was observed in the intestinal tissues of the MSCs-KGF group. Compared with the challenged control group, the DAI score, CMDI score and TDI score of the MSCs group, MSCs-vec group and MSCs-KGF group were markedly lower. Treatment with MSCs obviously promoted the expression of claudin-1 and PCNA in intestinal tissues of UC rats. Simultaneously, compared with the challenged control group, the levels of TNF- $\alpha$, IL-6 and IL-8 in the intestinal tissues of the MSCs groups were significantly decreased, while the levels of IL-10 were significantly increased. Most importantly, we found that MSCs-KGF significantly improved colonic morphology and tissue damage and inflammation in UC rats compared with MSCs and MSCs-vec. Further analysis showed that MSCs-KGF clearly promoted phosphorylation of PI3K and Akt and inhibited nuclear translocation of NF- $\kappa \mathrm{B}$ in intestinal tissues of UC rats.

Discussion: MSCs, especially KGF-modified MSCs, can improve colonic tissue damage in UC rats by promoting intestinal epithelial cell proliferation and reducing colonic inflammatory response, which may be related to activation of PI3K/Akt pathway and inhibition of $\mathrm{NF}-\kappa \mathrm{B}$ activation.

Keywords: ulcerative colitis, bone marrow mesenchymal stem cells, keratinocyte growth factor, gene modification, PI3K/Akt pathway, NF-кB

\section{Introduction}

Ulcerative colitis (UC) is a chronic non-specific colon disease that is often accompanied by varying degrees of intestinal inflammation and colonic mucosal damage. ${ }^{1}$ Mucosal damage can achieve a certain degree of self-reduction through the selfrepair, proliferation and differentiation of epithelial cells. However, persistent intestinal inflammation and ulceration can disrupt the intestinal repair system leading to refractory ulcers. ${ }^{2}$ Improving colonic mucosal inflammation and promoting mucosal repair are the key to treating UC. 
Mesenchymal stem cells (MSCs) have the characteristics of low immunogenicity, anti-inflammatory, tissues repair that can also sense changes in environmental signals and migrate to inflammatory tissues. ${ }^{3}$ MSCs have been found to be easily transfected with foreign genes and stably expressed recently. ${ }^{4}$ The original MSCs have shortcomings such as short survival time and low concentration of injury sites after implantation into the host, while genetically modified MSCs can overcome the above defects. ${ }^{5}$ The preparation of stem cells expressing multiple cytokine modifications by genetic engineering technology has been used for cell transplantation therapy, which also provides new ideas and prospects for the treatment of UC. ${ }^{6}$

Keratinocyte growth factor (KGF), which is also known as fibroblast growth factor (FGF)-7, has a wide range of cytokine activity. ${ }^{7} \mathrm{KGF}$ is derived from MSCs that plays an important role in the repair of various organs such as the gastrointestinal, thymus, lung, and kidney. ${ }^{8}$ Studies have confirmed that KGF can promote the recovery of epithelial function after small bowel resection, and the use of KGF gene therapy can significantly alleviate UC. ${ }^{9}$ It has recently been reported that KGF can promote epithelial differentiation of MSCs in vitro, ${ }^{10}$ suggesting that KGF may have some autocrine effects on MSCs themselves. Yao et $\mathrm{al}^{11}$ reported that KGF-pretreated MSCs can be transplanted into the lung tissue of rats with pulmonary fibrosis injury to improve lung injury and fibrosis. Additionally, Yang et $\mathrm{al}^{12}$ also found that KGF can enhance the repair of spinal cord injury in rats by MSCs transplantation. Based on these findings, we hypothesized that KGF may enhance the therapeutic effects of MSCs on UC.

The trinitrobenzene sulfonic acid (TNBS) method is a method for making animal models of UC in recent years. ${ }^{6}$ We introduced KGF gene into male rat bone marrow MSCs by adenovirus infection technique to observe the therapeutic effect of KGF gene-modified MSCs on TNBS-induced female UC rats. We look forward to providing new ideas for cell transplantation therapy for UC.

\section{Materials and Methods}

\section{Animals}

Sprague-Dawley (SD) rats were provided by Capital Medical University. Five male rats of 4 weeks old, weighing 100-120 g, were used to prepare MSCs. Six-week-old female rats weighing $250-280 \mathrm{~g}$ was used to prepare UC model. The feeding condition was SPF grade, and the circadian rhythm was $12 \mathrm{~h} / 12 \mathrm{~h}$. Normally supply drinks and water. All animal experiments performed in this study have been approved by Institutional Animal Care and Use Committee of Capital Medical University and accordance with the NIH Guide for the Care and Use of Laboratory Animals.

\section{Isolation, Culture and Identification of Bone MSCs}

Four-week-old male SD rats were immersed in $75 \%$ ethanol for $10 \mathrm{~min}$ after cervical dislocation and then transferred to a clean bench. The lower femur and tibia of the rat were harvested, the bone ends of both sides were cut, and the medullary cavity was repeatedly washed with serum-free DMEM medium (Gibco). The obtained bone marrow cell suspension was transferred to a centrifuge tube and centrifuged at $1000 \mathrm{r} / \mathrm{min}$ for $5 \mathrm{~min}$. The supernatant was discarded and the cells were resuspended in low sugar DMEM (Gibco) containing 10\% fetal calf serum. The cells were seeded in $25 \mathrm{~cm}^{2}$ medium and incubated in a $5 \% \mathrm{CO}_{2}$ incubator at $37^{\circ} \mathrm{C}$. The culture solution was changed every 3 days. When the cells were fused to $80 \%$ to $90 \%$, they were subcultured at $1: 2$. A $1 \times 10^{9} / \mathrm{L}$ single cell suspension was prepared from the 4th generation cells. Flow cytometry (FACSCalibur, Becton-Dickinson, Franklin Lakes, USA) was used to detected the expression of CD29, CD34, CD44 and CD45 for MSCs identification.

\section{Construction of KGF Lentiviral Vector and Infection of MSCs}

The 4th generation of MSCs was inoculated in the culture dish, and the amount of adenovirus was calculated according to the multiplicity of infection (MOI) of 100 after 24 h. The packaged KGF recombinant adenovirus (HANBIO, China) was added to the culture medium. Unmodified MSCs infected with an empty adenovirus without an inserted gene was used as a negative control. The expression of KGF in MSCs after lentivirus infection was detected by RT-PCR and Western blot analysis.

\section{RT-PCR}

Total RNA was extracted using Trizol reagent (Invitrogen, USA). The RNA concentration was determined by an ultraviolet spectrophotometer (BIO-TEK, USA). RT-PCR reactions were performed using the $\mathrm{ABI} 7500$ system (ABI, USA). GAPDH was used as an internal reference. 
The fold change in relative expression of mRNA was calculated by the $2^{-\Delta \Delta \mathrm{Ct}}$ method.

\section{Western Blot}

Total proteins were extracted after lysis by RIPA (Invitrogen, USA). The protein concentration was determined by the BCA method. The protein was separated by electrophoresis on $10 \%$ SDS-PAGE and transferred to a polyvinylidene fluoride membrane. The membrane was washed with TBST and blocked by shaking at room temperature for 1 h. Membranes were incubated with the corresponding primary antibody overnight at $4^{\circ} \mathrm{C}$. After washing with TBST, the membrane was incubated with HRP-conjugated secondary antibody (Santa Cruz Biotechnology) for $1 \mathrm{~h}$ at room temperature. Development was performed using enhanced chemiluminescence detection (ECL) (Amersham Corp., Arlington Heights, IL). Relative protein expression levels were assessed using Image $\mathrm{J}$ image analysis software (National Institutes of Health, Bethesda, MD, USA) and Quantity One software (Bio-Rad, USA).

\section{TNBS-Induced Colitis Model Establishment}

A rat model of colitis was induced according to reference. ${ }^{6}$ Six-week-old rats were fasted for $48 \mathrm{~h}$ before modeling. Then, the rats were stimulated to expel stools at the distal end of the large intestine. Rats were anesthetized by intraperitoneal injection of sodium pentobarbital $(30 \mathrm{mg} / \mathrm{kg}$ ) after emptying stool. The tail of the rat was allowed to stand upside down. A silicone tube with a diameter of $2.0 \mathrm{~mm}$ and a length of $12 \mathrm{~cm}$ was gently inserted from the anus into the colon $8 \mathrm{~cm}$ from the anal margin. TNBS (Sigma-Aldrich, USA) dissolved in $0.25 \mathrm{~mL} \mathrm{50 \%} \mathrm{50 \%} \mathrm{etha-}$ nol solution, was injected into the colon through the polyethylene catheter at a dose of $80 \mathrm{mg} / \mathrm{kg}$ body weight, finished in $5 \mathrm{~s}$. After the filling, maintain the inverted position for $30 \mathrm{~s}$ to $60 \mathrm{~s}$ to prevent the liquid from leaking out.

\section{Experimental Grouping and Processing}

The next day after TNBS injection, rats were randomly divided into 3 groups, 10 in each group: challenged control group, MSCs group, MSCs-vec group and MSCs-KGF group. Tail vein injection was used to transplant bone marrow MSCs. Each rat was injected with $1 \mathrm{~mL}$ of the cell suspension, and the cell density was adjusted to $3 \times 10^{6} / \mathrm{mL}$. The challenged control group only injected DMEM medium. The MSCs group was injected with cell suspension containing MSCs. The MSCs-vec group was injected with cell suspensions of MSCs infected with empty lentivirus. The MSCs-KGF group was injected with KGF gene-modified MSCs cell suspension. SD rats treated without any intervention were used as a control group. Seven days after tail vein injection, histological analysis was performed.

\section{Experimental Design}

After TNBS induction modeling, the rats' mental state, activity, hair luster and diet were observed at fixed time intervals, and the body mass changes, stool traits and blood in the stool were recorded for disease activity index (DAI) score. ${ }^{13}$ Severity scores for UC are $0-4$ (Table 1). After the completion of MSCs treatment, all animals were sacrificed after $24 \mathrm{~h}$ of fasting. The distal large intestine was taken about $10 \mathrm{~cm}$, and after longitudinal incision, the intestines were washed with icecold saline. The damage of the intestinal mucosa was observed, and the colonic crotal damage index (CMDI) score of the colon tissue was performed. ${ }^{14}$ The scoring criteria are shown in Table 2. Cut some of the diseased intestinal tissue, a portion was immediately fixed in $4 \%$ paraformaldehyde, and embedded in paraffin-embedded sections $(5 \mu \mathrm{m})$ for HE staining and immunohistochemistry; a portion was frozen at $-80^{\circ} \mathrm{C}$ for enzyme-linked immunosorbent assay (ELISA) and Western blot analysis.

\section{Hematoxylin-Eosin (HE) Staining and Tissue Damage Index (TDI) Score}

The paraffin-embedded sections were taken, dewaxed and dehydrated, and subjected to conventional hematoxylineosin staining. After dehydration by alcohol and xylene, the slices were air-dried. Sealed with a neutral gum. Pathological changes of intestinal tissue were observed under light microscope. TDI scores of sections were performed according to the Cooper HS standard. ${ }^{13}$ In brief, the sections were graded by two blinded investigators,

Table I The Standard of DAI Score

\begin{tabular}{|l|l|l|l|}
\hline Score & $\begin{array}{l}\text { Decline in Body } \\
\text { Weight (\%) }\end{array}$ & $\begin{array}{l}\text { Stool } \\
\text { Consistency }\end{array}$ & $\begin{array}{l}\text { Occult } \\
\text { Blood }\end{array}$ \\
\hline 0 & Naught & Normal & Negative \\
1 & $1-5$ & - & - \\
2 & $5-10$ & Soft & Positive \\
3 & $10-15$ & - & - \\
4 & $>15$ & Liquid & Visible \\
\hline
\end{tabular}


Table 2 The Standard of CMDI Score

\begin{tabular}{|l|l|}
\hline Feature & Score \\
\hline Ulcer & \\
None & 0 \\
Hyperemia, no ulcers & I \\
Point or linear ulcers without obvious inflammation & 2 \\
One ulcer with apparent inflammation & 3 \\
Two or more ulcers with obvious inflammation & 4 \\
Two or more ulcers with obvious inflammation, or one & 5 \\
ulcer with a range exceeding I cm & 6 \\
Ulcers over 2cm & \\
Adhesion & 0 \\
None & 1 \\
Slight adhesion & 2 \\
Severe adhesion & \\
\hline
\end{tabular}

including a range from 0 to 3 for inflammation or extent of inflammation, a range from 0 to 4 for the amount of crypt damage or regeneration. These changes were also quantified as to the percentage involvement by the disease process. As shown in the Table 3 .

\section{ELISA}

The frozen intestinal tissue was placed in a test tube, and homogenized in an ice bath by adding 9 volumes of icecold PBS buffer ( $\mathrm{pH}$ 7.4). The contents of TNF- $\alpha$, IL-10, IL-6 and IL- 8 were detected by TNF- $\alpha$, IL-10, IL-6 and IL-8 ELISA kit (Elabscience Biotechnology, Wuhan, China) employing the quantitative sandwich enzyme immunoassay technique, respectively. All operations were carried out in strict accordance with the kit instructions.

\section{Immunohistochemical Analysis}

Intestinal paraffin sections $(5 \mu \mathrm{m})$ were dewaxed with xylene and hydrated with a gradient alcohol. After incubating in citrate buffer at $95^{\circ} \mathrm{C}$ for $15 \mathrm{~min}$, the peroxidase blocker was added for $30 \mathrm{~min}$. After washing with PBS, it was incubated for $30 \mathrm{~min}$ in normal non-immune serum. The sections were incubated with Claudin-1, PCNA and $\mathrm{KGF}$ primary antibody at $37^{\circ} \mathrm{C}$ for $1 \mathrm{~h}$. After incubation with biotinylated secondary antibody for $30 \mathrm{~min}$, it was incubated with streptomycin avidin-peroxidase for $15 \mathrm{~min}$. Sections incubated with PBS served as negative controls. After washing with PBS, the DAB solution was added. After counterstaining with hematoxylin, dehydration with gradient alcohol, and transparent xylene, the tablets were sealed with neutral gum. Protein positive expression was observed under a microscope. Three visual fields of each
Table 3 The Standard of TDI Score

\begin{tabular}{|l|l|}
\hline Feature & Score \\
\hline Severity of inflammation & \\
None & 0 \\
Mild & 1 \\
Moderate & 2 \\
Severe & 3 \\
\hline Extent of inflammation & \\
None & 0 \\
Mucosa & 1 \\
Mucosa and submucosa & 2 \\
Transmural & 3 \\
\hline Regeneration & \\
No tissue repair & 4 \\
Surface epithelium not intact & 3 \\
Regeneration with crypt depletion & 2 \\
Almost complete regeneration & 1 \\
Complete regeneration or normal tissue & 0 \\
\hline Crypt damage & \\
None & 0 \\
I/3 damaged & 1 \\
$2 / 3$ damaged & 2 \\
Crypts lost, surface epithelium present & 3 \\
Crypts lost and surface epithelium lost & \\
\hline Percent involvement & 1 \\
0 & 2 \\
I-20\% & 3 \\
$26-50 \%$ & \\
5 I-75\% & \\
$76-100 \%$ & \\
\hline
\end{tabular}

section were randomly selected for detecting the relative intensity of the positive expression.

\section{Statistical Analysis}

Statistical analyses were performed using SPSS 13.0 software (SPSS, Inc., Chicago, IL, USA). Data were expressed as mean \pm standard deviation (SD). Results were analyzed using the Student's t tests or one-way analysis of variance for multiple comparisons. $\mathrm{p}<0.05$ was considered to represent statistically significant difference.

\section{Results}

\section{Morphology and Identification of SD Rat Bone Marrow MSCs}

Microscopically, the primary MSCs were spindle-shaped, triangular and polygonal (Figure 1Aa). After passage, the cell growth rate was obviously accelerated, and the cells 
A

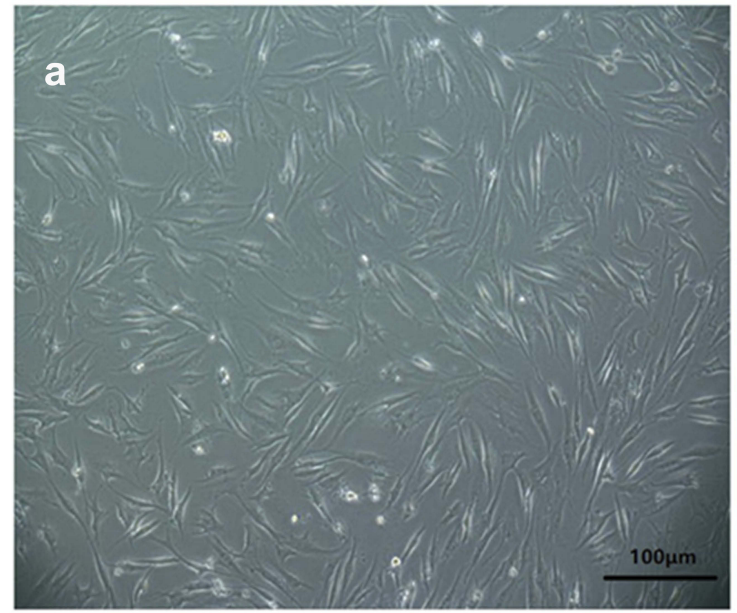

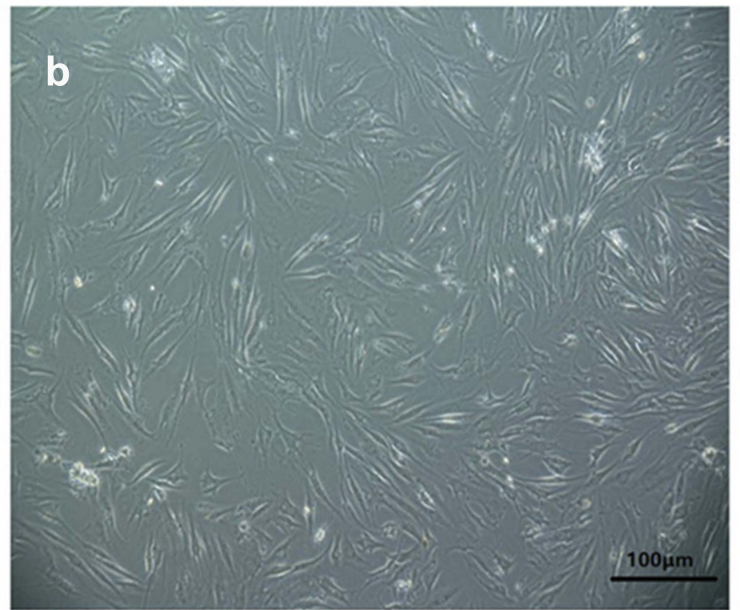

B

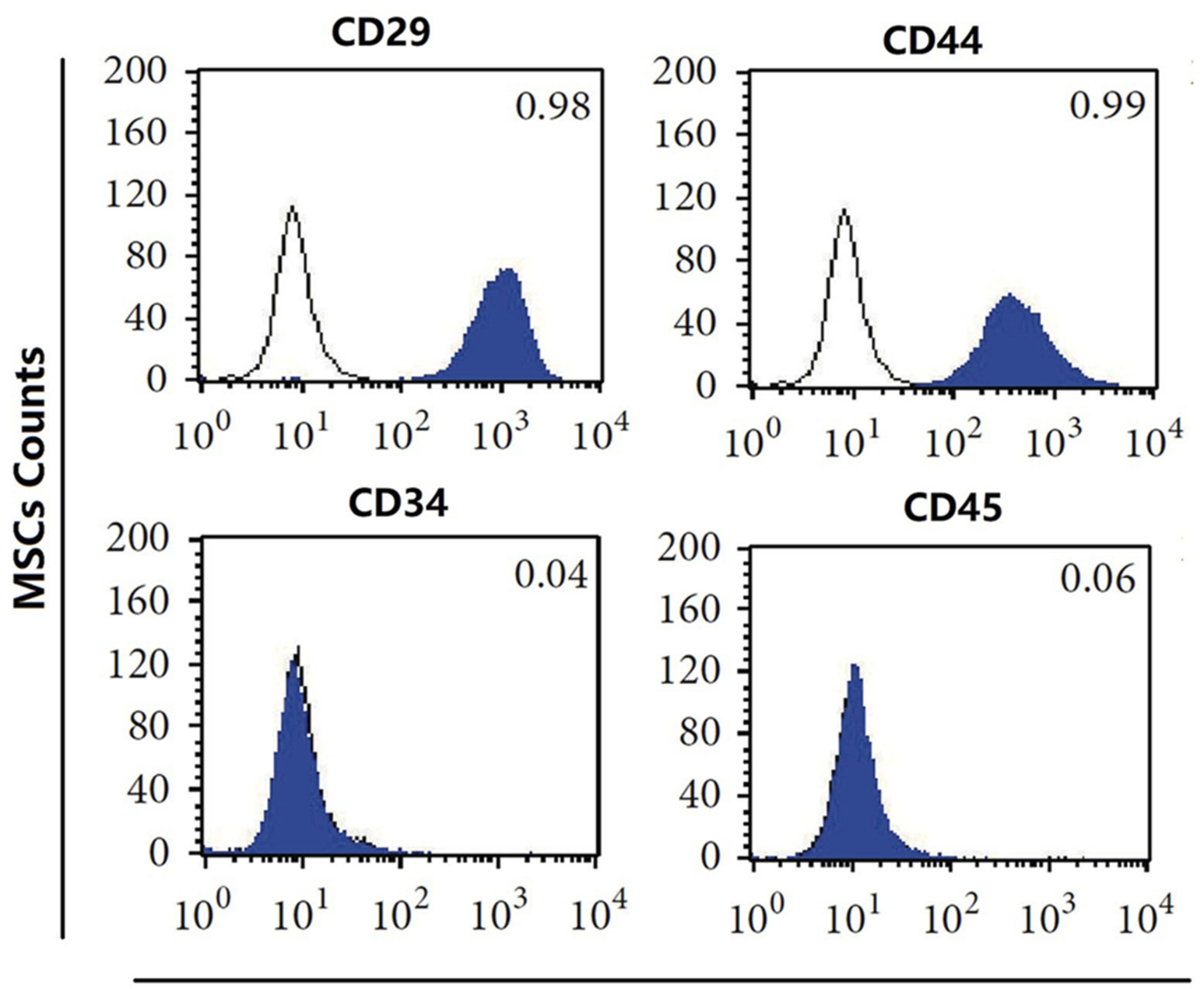

FL1-H

Figure I Morphology and identification of bone marrow MSCs from SD male rats. (A) Morphology of rat MSCs from primary (a) and 4th generation (b) was observed under a phase contrast microscope. Scale bar $=100 \mu \mathrm{m}$. (B) Flow cytometry was used to detect the expression of CD antigen on the surface of 4 th generation MSCs in rats. Abbreviation: MSCs, mesenchymal stem cells. 
were still fusiform or polygonal. The 4th generation of MSCs could be significantly purified (Figure 1Ab). Then the MSCs were identified by flow cytometry (Figure 1B). The 4th generation of MSCs expressed CD29 $(0.99 \pm 0.01)$ and CD44 (1.00 \pm 0.01$)$, and did not express CD34 $(0.04 \pm 0.01)$ and CD45 (0.03 \pm 0.02$)$, suggesting that the cells were MSCs.

\section{Expression of KGF in MSCs After}

\section{Lentivirus Infection}

We further used RT-PCR and Western blot to detect the expression of KGF mRNA and protein after infection of MSCs by KGF lentiviral vector (MSCs-KGF) and empty vector (MSCs-vec). Using untreated MSCs as a baseline reference. KGF mRNA expression in the MSCs-KGF group (2.323 \pm 0.812$)$ was significantly higher than that in the MSCs group $(0.824 \pm 0.313)(p<0.05$, Figure 2A). Meanwhile, KGF protein expression was significantly increased in the MSCs-KGF group $(2.585 \pm 0.883)$ compared with the MSCs group $(0.865 \pm 0.462)$ and the MSCs-vec group $(0.838 \pm 0.458)(\mathrm{p}<0.05$, Figure 2B). These results suggested that KGF is overexpressed in MSCs infected with a lentiviral vector carrying the KGF gene.

\section{Expression of Adeno, SRY and KGF in Intestinal Tissues}

In order to clarify the colonization of MSCs derived from male rats in the colon tissues of female rats, we examined whether there is SRY (sex determining genes) and Adeno (adenovirus gene) in colon tissue of female rats. Adeno and SRY were abundantly expressed in the intestinal tissues of MSCs group (0.916 $\pm 0.428,0.797 \pm 0.328)$, MSCs-vec group $(0.923 \pm 0.409,0.796 \pm 0.511)$ and MSCs-KGF group (3.047 $\pm 0.664,2.613 \pm 1.007$ ), while the expression of Adeno and SRY were barely detected in the control group and challenged control group (Figure 3A and B). These results suggest that transplanted male rat MSCs can colonize the colon tissue of female rats, and these MSCs are adenovirus modified. Significantly, Adeno and SRY expression in colon tissue of MSCs-KGF group were significantly higher than those of MSCs group and MSCs-vec group.

Further analysis of the expression of KGF protein in colon tissue showed that almost no expression of KGF was detected in the colon tissue of the control and challenged control challenged control groups (Figure 3C). The KGF mRNA and protein expression were significantly increased in the MSCs-KGF group (1.159 $\pm 0.521,1.121 \pm 0.379)$ compared to the challenged control group $(0.007 \pm 0.001,0.010$ $\pm 0.010)(\mathrm{p}<0.05$, Figure $3 \mathrm{C})$. Simultaneously, KGF mRNA and protein expression in MSCs-KGF group were significantly higher than those in MSCs $(0.230 \pm 0.101,0.116$ $\pm 0.017)$ and MSCs-vec $(0.217 \pm 0.059,0.119 \pm 0.017)$ groups $(\mathrm{p}<0.05$, Figure $3 \mathrm{C})$. Additionally, Immunohistochemical analysis showed positive expression of KGF in colon tissue of rats treated with MSCs (Figure 3D). These results suggested that KGF promotes the entry of MSCs into the colon site of TNBS-induced injury and can express KGF at the injury site of colon tissue.
A

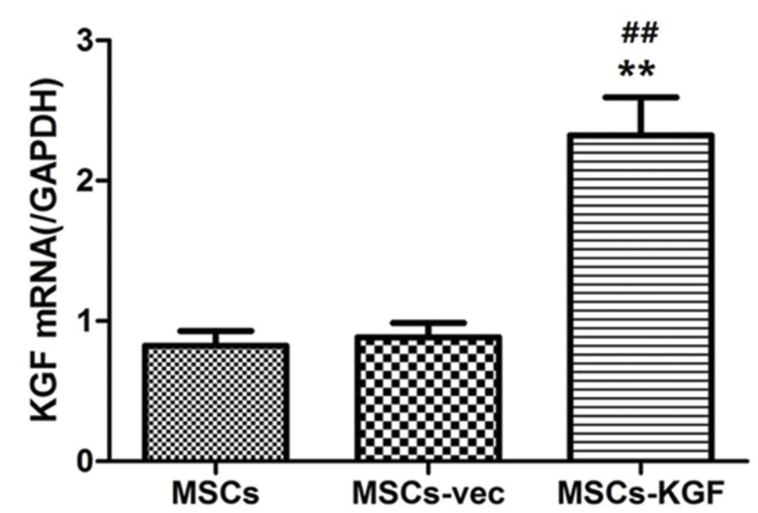

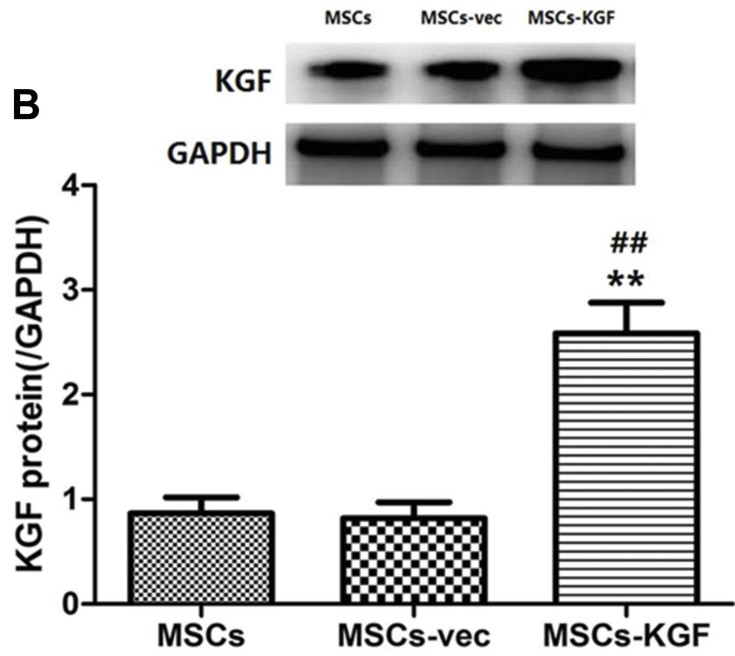

Figure 2 Expression of KGF in MSCs following lentivirus infection. The expression of KGF mRNA (A) and protein (B) in MSCs carrying empty vector (MSCs-vec) or carrying KGF expression gene (MSCs-KGF) was detected by qRT-PCR and Western blot assay. Untreated MSCs cells were used as baseline reference (MSCs). $n=10$. Data shown are mean $\pm S D$. ${ }^{* *} p<0.01$ vs MSCs group; ${ }^{*} p<0.01$ vs MSCs-vec group.

Abbreviations: MSCs, mesenchymal stem cells; KGF, keratinocyte growth factor. 

A
control
$\infty$ challenged control
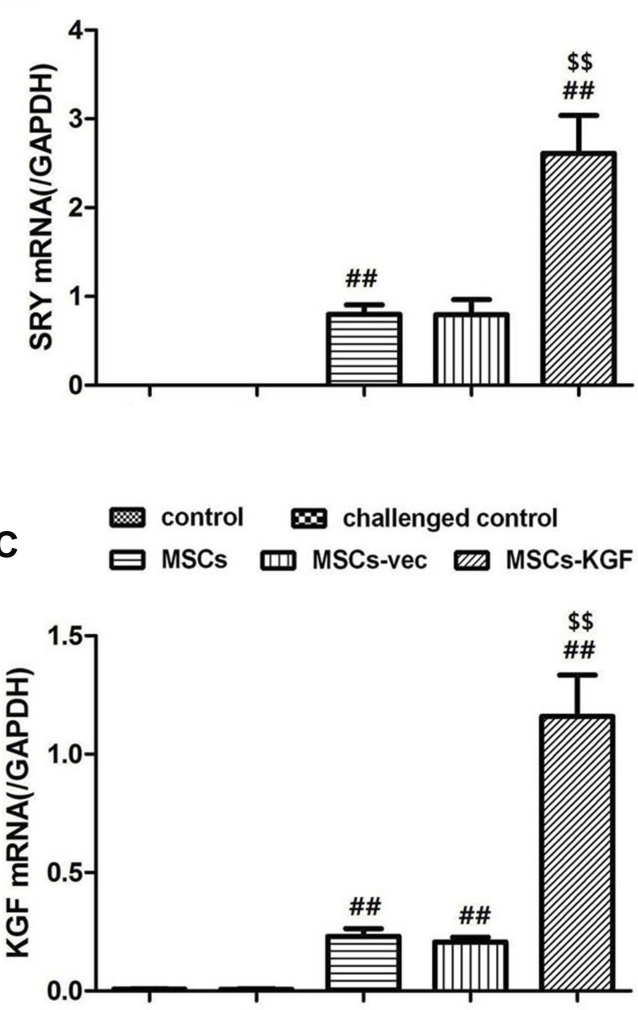

C control $\infty$ challenged control
$\square$ MSCs $⿴ 囗 十$ MSCs-vec m MSCs-KGF

control $\infty$ challenged control

B $\square$ MSCs 血 MSCs-vec m mSCs-KGF

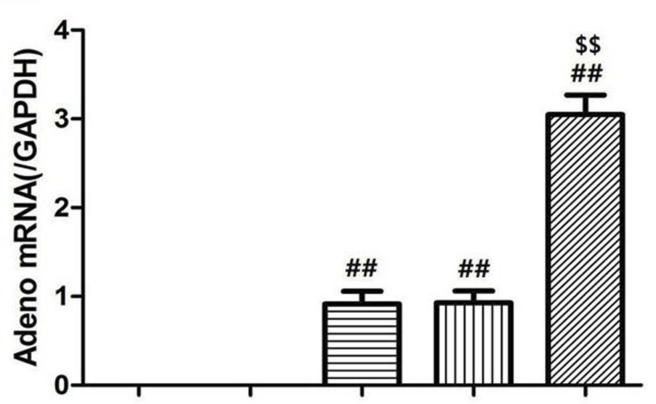

$\times$ control $\infty$ challenged control

曰 MSCs m mSCs-vec m MSCs-KGF

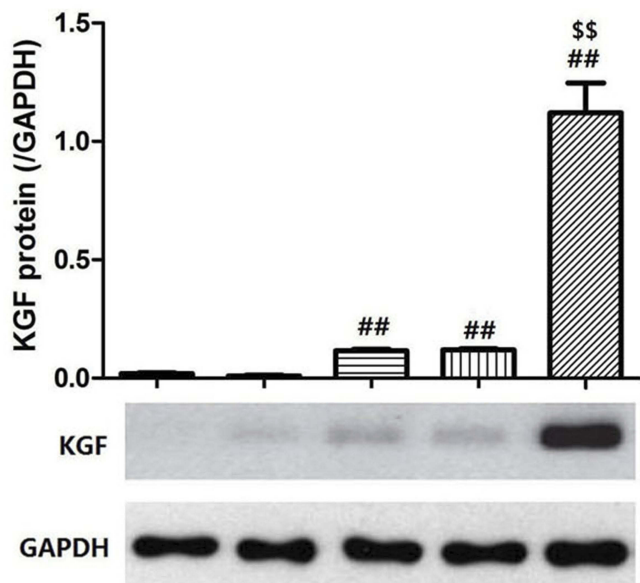

D control

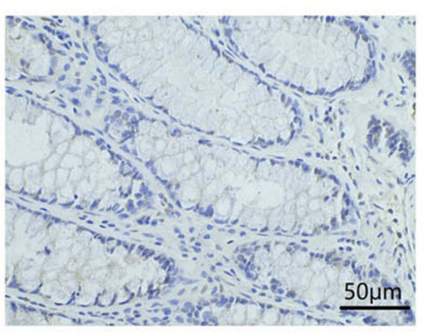

challenged control
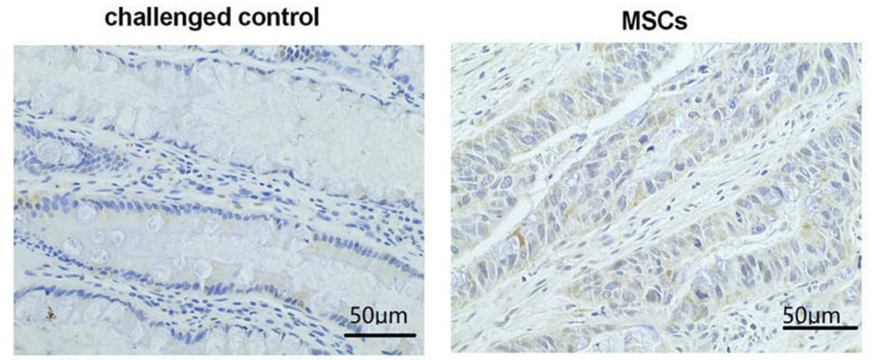

MSCs-vec

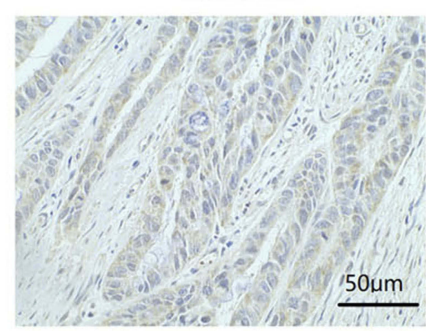

MSCs-KGF

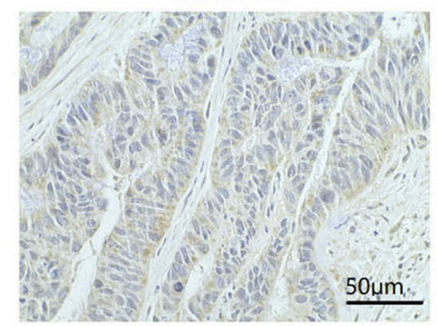

Figure 3 Expression of Adeno, SRY and KGF in intestinal tissue. Female SD rats were induced by TNBS to establish UC model, and then treated with MSCs, which untreated MSCs (MSCs), MSCs carrying empty vector (MSCs-vec) and MSCs carrying KGF gene (MSCs-KGF), respectively. UC rats in the Model group were treated with only DMEM medium. SD female rats treated without any intervention were used as a control group. After I week of treatment, the expression of Adeno (A) and SRY (B) in intestinal tissues was detected by qRT-PCR. At the same time, the expression of KGF mRNA and protein in the intestinal tissues of each group was examined by qRT-PCR and Western blot assay (C). (D) Immunohistochemistry images from the intestinal tissues of rats for KGF. Scale bar $=50 \mu \mathrm{m}$. $n=10$. Data shown are mean $\pm S D$. ${ }^{\#}{ }^{\mathrm{p}}<0.0 \mathrm{lvs}$ Model group; ${ }^{\$} \mathrm{p}<0.0$ lvs MSCs group.

Abbreviations: UC, ulcerative colitis; MSCs, mesenchymal stem cells; KGF, keratinocyte growth factor. 


\section{General Status, DAI Score and CMDI Score}

The rats in the control group were sensitive, the hair was shiny and the diet was normal. From the second day after TNBS enema, the rats in the challenged control group began to show varying degrees of wilting, less movement, hair dullness, reduced diet, diarrhea and blood in the stool. Symptoms similar to the challenged control group also appeared in the MSCs group and the MSCs-vec group, but were relieved compared with the challenged control group. Simultaneously, the symptoms of the rats in the MSCs-KGF group were the lightest, and no blood in the stool was observed.

After 7 days of injected with MSCs, the DAI scores of the MSCs(2.1 \pm 0.7$)$, MSCs-vec(2.1 \pm 0.7$)$, and MSCs-KGF (1.4 \pm 0.4$)$ groups were significantly lower compared to the challenged control group $(3.9 \pm 0.3)(\mathrm{p}<0.05$, Figure 4A). We also found that the DAI scores of the MSCs-KGF group were significantly lower than those of the MSCs group and the MSCs-vec group ( $<<0.05$, Figure 4A). Treatment of MSCs significantly reduced CMDI scores in UC rats $(\mathrm{p}<0.05$, Figure $4 \mathrm{C})$. Furthermore, the CMDI

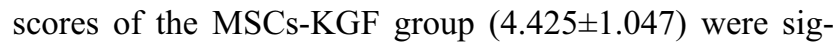
nificantly lower than those of the MSCs group (6.277 $\pm 1.082)$ and the MSCs-vec group (6.132 \pm 1.090$)$ $(\mathrm{p}<0.05$, Figure 4C).

\section{Pathological Observation}

Rats intestinal tissues were taken for HE staining. The rat in the control group had normal colon morphology. The structure of the colonic mucosa in the challenged control group was severely damaged, disorders or loss of glandular arrangement, a large number of inflammatory cell infiltrations and crypt inflammation and abscess formation were observed in the interstitial tissue of the colon. The pathological damage of colon tissue in MSCs group, MSCs-vec group and MSCs-KGF group was alleviated to a different extent than that in challenged control group, especially in MSCs-KGF group (Figure 5A). The challenged control group had a significant increase in TDI scores compared to the control group ( $\mathrm{p}<0.05$, Figure 5B). Treatment with MSCs significantly reduced the TDI score in UC rats $(\mathrm{p}<0.05$, Figure 5B). Moreover, we found that the TDI scores of the MSCs-KGF group were significantly lower than those of the MSCs group and the MSCs-vec group $(\mathrm{p}<0.05$, Figure 5B).

\section{The Expression of Claudin-I and PCNA}

We used immunohistochemistry and Western blot assay to analyze the expression of the tight junction protein Claudin-1 in rat intestinal tissue. The expression of Claudin-1 in normal colon tissue was gridded (control group), while it was discontinued in the challenged control group, and its local expression was diffusely and broken (Figure 6A). Compared with the challenged control group, MSCs treatment significantly increased the expression of Claudin-1 in colon tissue of UC rats (Figure 6B). Additionally, Claudin-1 expression in the MSCs-KGF group was significantly higher than that in the MSCs group and the MSCs-vec group ( $\mathrm{p}<0.05$, Figure 6), suggesting that MSCs-KGF promotes the repair of the intestinal epithelial barrier in UC rats.

PCNA is a good indicator of the proliferation activity of epithelial cells. We found that TNBS induction reduced the expression of PCNA in colonic epithelial cells of UC rats to inhibit the proliferation of intestinal mucosal epithelial cells, while MSCs promoted intestinal mucosal epithelial cell proliferation and protected intestinal mucosal epithelial cells (Figure 6A). We also found that the expression of PCNA in the MSCs-KGF group was significantly higher than that in the MSCs group and the MSCs-vec group (Figure 6B). These results suggested that MSCsKGF can alleviate intestinal structural and functional damage in UC rats by promoting intestinal mucosal epithelial cell proliferation.

\section{Concentration of TNF- $\alpha$, IL- 6 and IL- 10}

The imbalance of inflammatory and anti-inflammatory factors in the colon leads to the development of UC. ${ }^{15}$ Compared with the control group, the levels of TNF- $\alpha$, IL-6 and IL-8 in the intestinal tissues of the challenged control group were significantly increased, while the levels of IL-10 were significantly decreased ( $p<0.05$, Figure 7). Compared with the challenged control group, the levels of TNF- $\alpha$ and IL- 6 in the intestinal tissues of the MSCs group, the MSCs-vec group and the MSCs-KGF group were significantly decreased, and the IL-10 level was significantly increased ( $p<0.05$, Figure 7 ), suggesting that MSCs treatment can improve the inflammatory response in UC rats. Furthermore, we also found that MSCs-KGF was obviously better than MSCs and MSCs-vec in the improvement of inflammation in intestinal tissues of UC rats $(\mathrm{p}<0.05$, Figure 7$)$. 
A

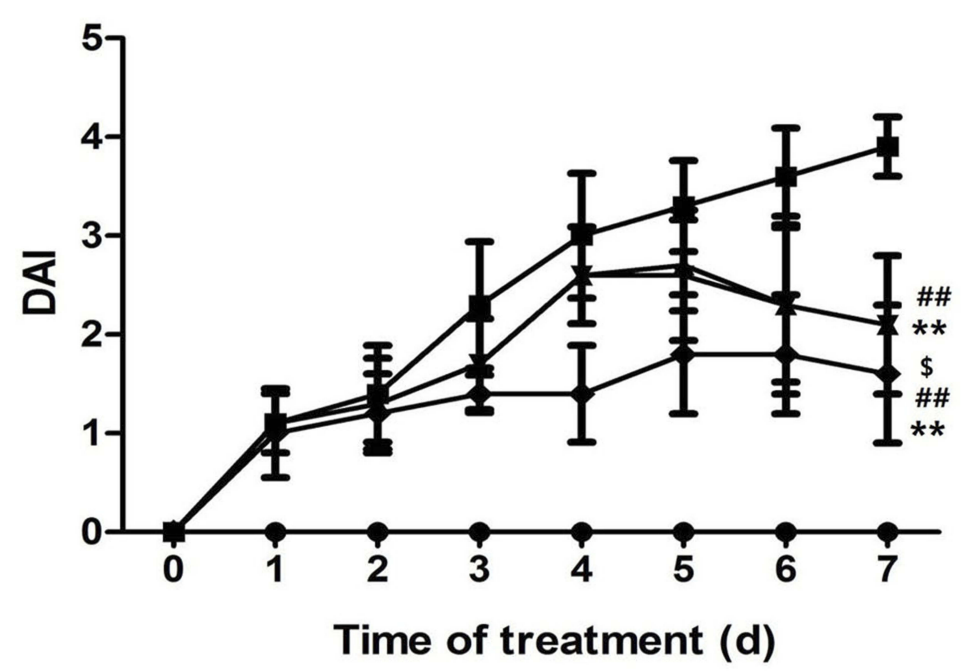

control

$\rightarrow$ challenged control

\pm MSCs

$\rightarrow$ MSCs-vec

$\rightarrow$ MSCs-KGF
B

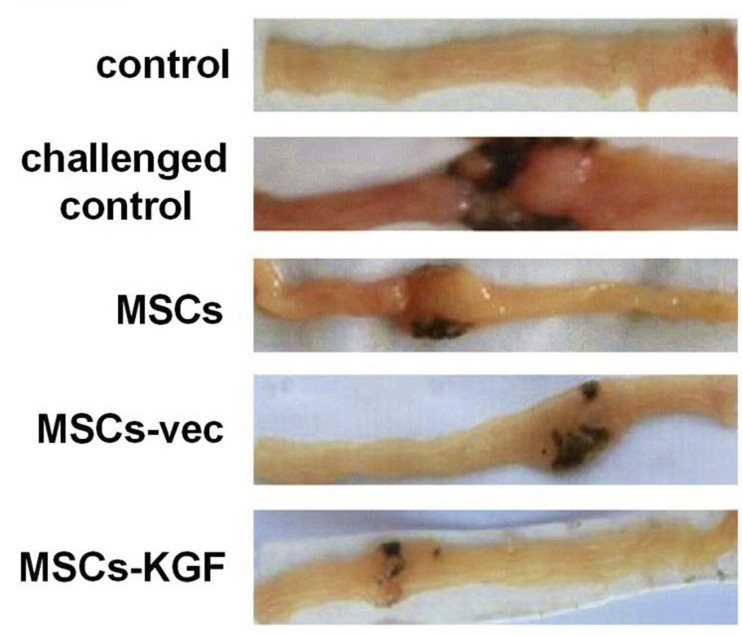

C

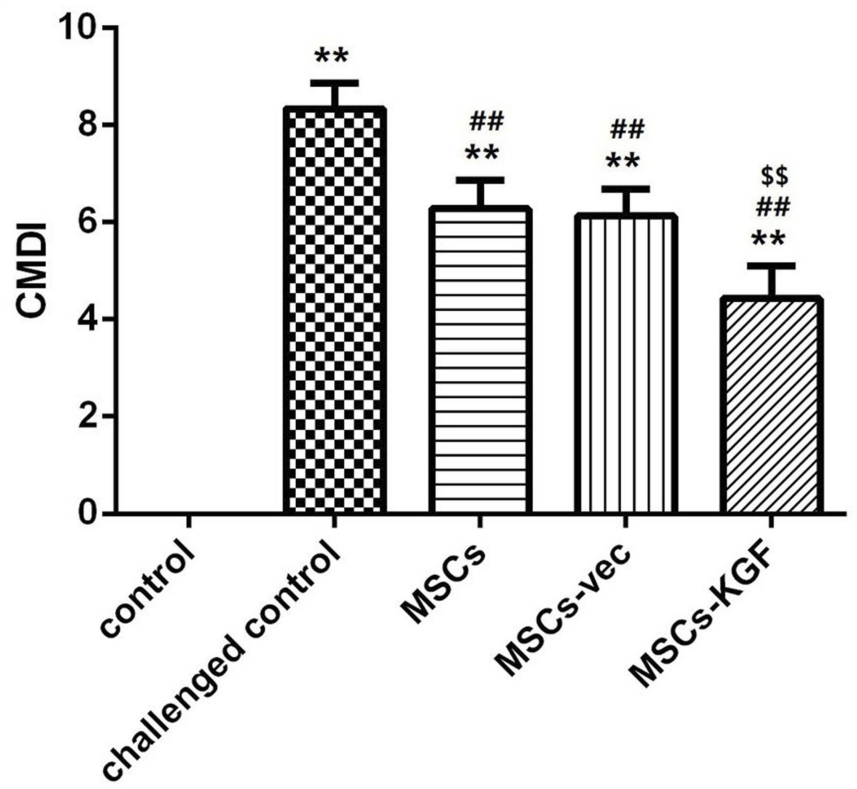

Figure 4 DAl score and CMDI score. The general status of each group of rats was observed from the induction of TNBS and the DAI score (A) was recorded. After 7 days of treatment of MSCs, rat intestinal tissue was taken for biopsy (B) and the CMDI score (C) was recorded. $n=I 0$. Data shown are mean $\pm S D$. $* * p<0.0 I$ vs control group; \# $\mathrm{p}<0.0$ Ivs Model group; ${ }^{\$} \mathrm{p}<0.05,{ }^{\$} \$ \mathrm{p}<0.0$ Ivs MSCs group.

Abbreviations: MSCs, mesenchymal stem cells; KGF, keratinocyte growth factor

\section{Effects of MSCs-KGF Treatment on PI3K/} Akt Signaling Pathway and NF-кB Pathway in Intestinal Tissues of UC Rats

We investigated the possible mechanism of MSCs-KGF treatment for colonic injury repair in $\mathrm{UC}$ rats by analyzing PI3K/Akt. The levels of p-PI3K/PI3K and p-Akt/Akt in the colon tissue of the challenged control group $(0.36$ $\pm 0.12,0.32 \pm 0.13$ ) were significantly lower compared to the control group $(0.91 \pm 0.11,0.93 \pm 0.13) \quad(\mathrm{p}<0.05$, Figure $8 \mathrm{~A}$ and $\mathrm{B}$ ). MSCs-KGF treatment significantly increased the levels of $\mathrm{p}-\mathrm{PI} 3 \mathrm{~K} / \mathrm{PI} 3 \mathrm{~K}$ and $\mathrm{p}$-Akt/Akt in intestinal tissues of $\mathrm{UC}$ rats $(0.84 \pm 0.14,0.82 \pm 0.13$, $\mathrm{p}<0.05$, Figure $8 \mathrm{~A}$ and $\mathrm{B})$, suggesting that MSCs-KGF can promote phosphorylation of PI3K and Akt, but does not affect total Protein expression. Additionally, although the phosphorylation levels of PI3K and Akt in the colon 

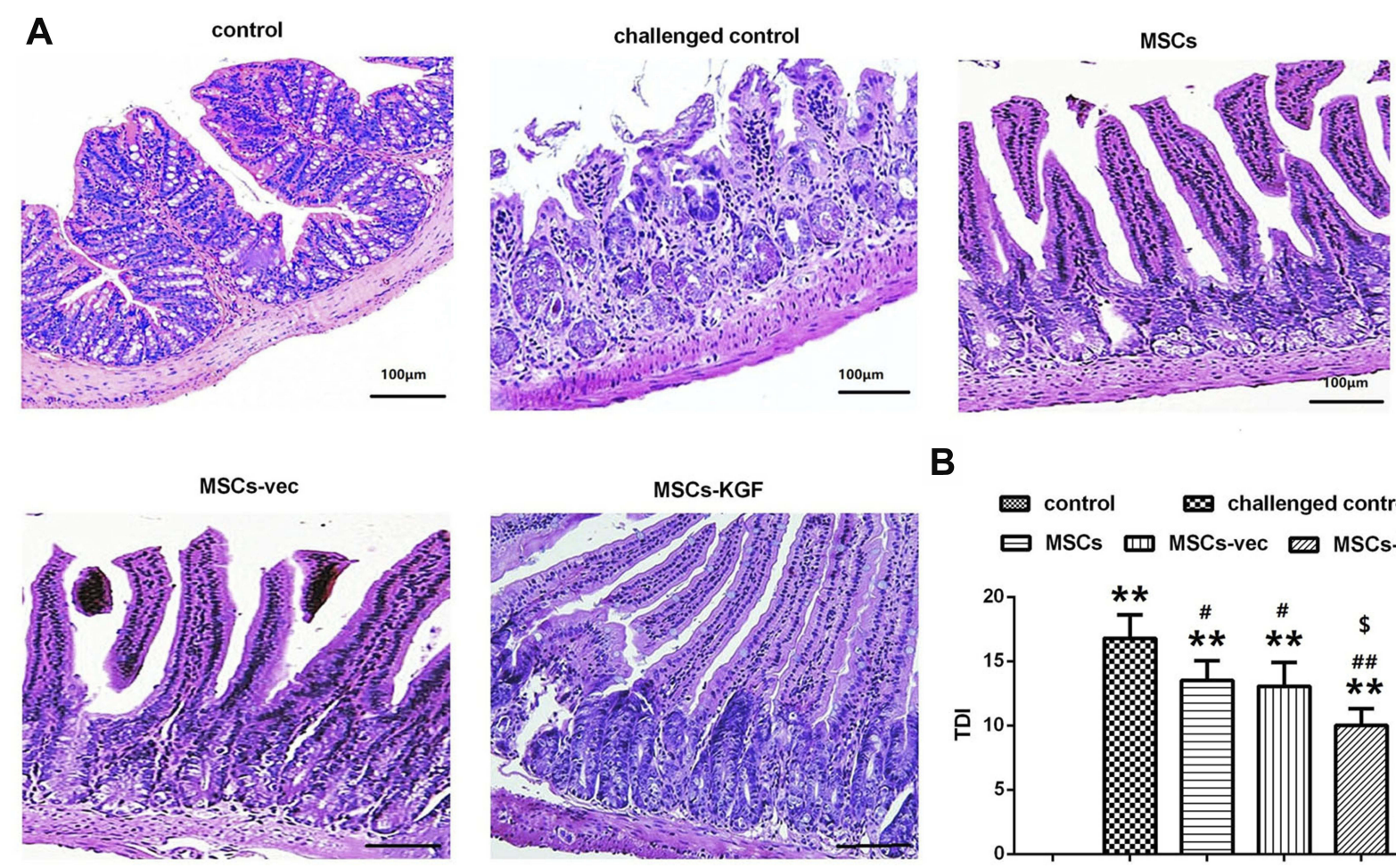

B
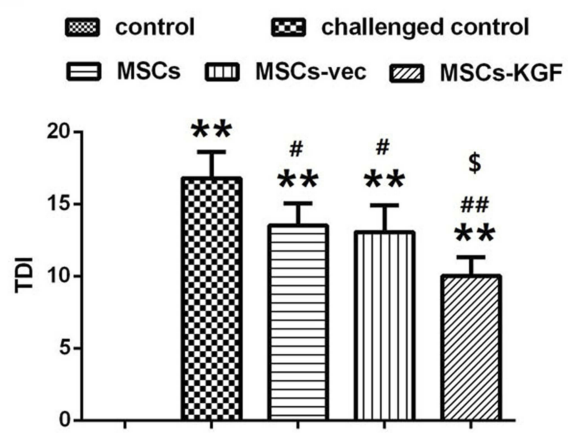

Figure 5 Pathological observation and TDI score. (A) HE staining was used to observe the pathological changes of intestinal tissue in each group of rats. Scale bar $=100 \mu \mathrm{m}$. (B) Comparison of TDI scores of rats in each group. $n=10$. Data shown are mean $\pm S D$. ${ }^{*} p<0.01$ vs control group; ${ }^{\#}<<0.05,{ }^{m} p<0.01$, vs Model group; ${ }^{\$} p<0.05$, vs MSCs group. Abbreviations: MSCs, mesenchymal stem cells; KGF, keratinocyte growth factor.

tissue of MSCs $(0.41 \pm 0.14,0.38 \pm 0.13)$ and MSCs-vec were increased, there was no significant difference compared with the challenged control group (Figure $8 \mathrm{~A}$ and $\mathrm{B}$ ).

We further analyzed the effect of MSCs-KGF treatment on $N F-\kappa B$ in intestinal tissues of UC rats. We found that the expression of p65 in the nucleus of the challenged control group $(0.951 \pm 0.204)$ was significantly higher than that of the control group $(0.156 \pm 0.068)(\mathrm{p}<0.05$, Figure $8 \mathrm{C}$ ), suggesting the activation of NF- $\kappa \mathrm{B}$ in the colon tissue of UC rats, which may be related to the decrease of IкB levels in the cytoplasm. MSCs treatment significantly inhibited the degradation of I $\mathrm{B}$ and nuclear translocation of NF- $\kappa \mathrm{B}$ p65 (Figure $8 \mathrm{C}$ and D). Furhtermore, the expression level of p65 in the nucleus of MSCs-KGF group $(0.415 \pm 0.126)$ was significantly lower than that of MSCs group $(0.563 \pm 0.119)$ and MSCs-vec group $(0.573 \pm 0.108)$ ( $<<0.05$, Figure $8 C)$.

\section{Discussion}

MSCs are of great significance in the repair of a variety of tissues due to their multi-directional differentiation potential, tissue repair capacity, anti-inflammatory effects and immunomodulatory properties. ${ }^{16,17}$ MSCs secrete a variety of factors through autocrine and paracrine pathways, which are involved in tissue damage repair by promoting cell proliferation, inhibiting apoptosis, and regulating inflammatory responses. ${ }^{18}$ Studies have confirmed that MSCs have potential therapeutic effects in acute myocardial infarction, acute renal failure, and inflammatory bowel disease. ${ }^{19,20}$ Forbes et $\mathrm{al}^{21}$ demonstrated that administration of MSCs can reduce CD activity index (CDAI) and $\mathrm{CD}$ endoscopic index of severity (CDEIS) scores in patients with luminal Crohn's disease (CD) refractory to biologic therapy. Zhang et al ${ }^{19}$ showed that MSCs can be colonized in colon tissue of UC rats, and can inhibit the inflammatory response in UC colon tissue and repair damaged colon mucosa. He et $\mathrm{al}^{22}$ found that peripheral intravenous infusion of MSCs can significantly improve the symptoms and intestinal tissue inflammation of mice with acute colitis induced by dextran sodium sulfate. The UC models we used in the study were made from female rats, while MSCs were isolated from the bone marrow of male rats. We found that each MSCs transplantation group highly expressed the lentivirus-related gene Adeno and the sex-determining gene SRY. The results confirmed the 


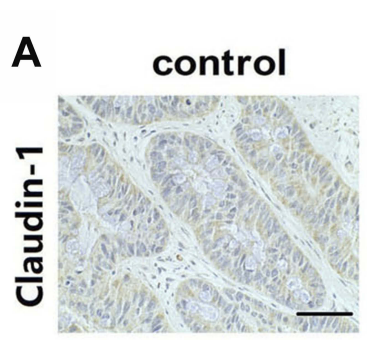

challenged control
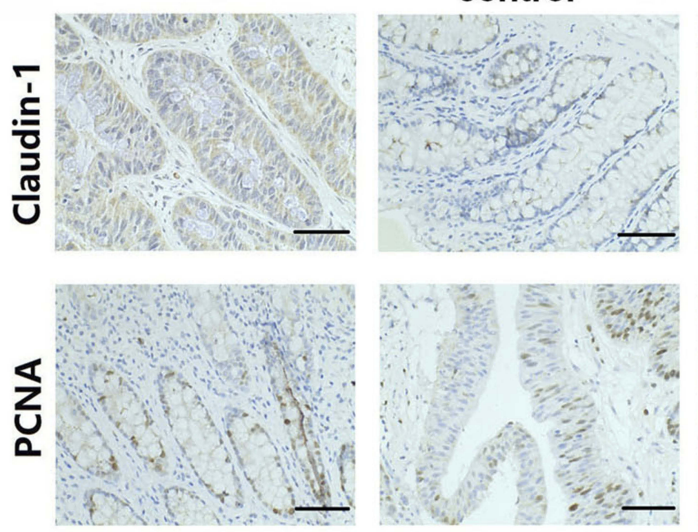

B

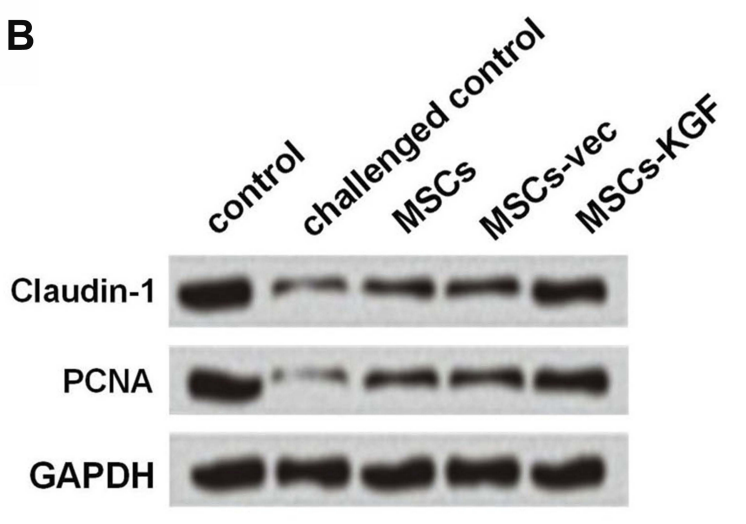

MSCs
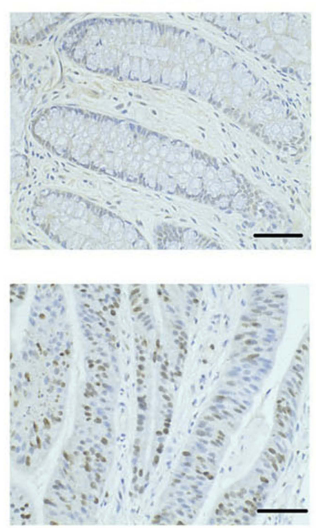

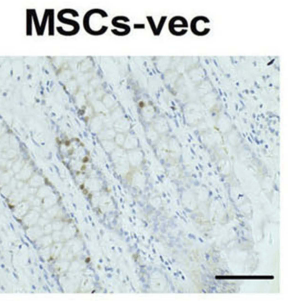

MSCs-KGF
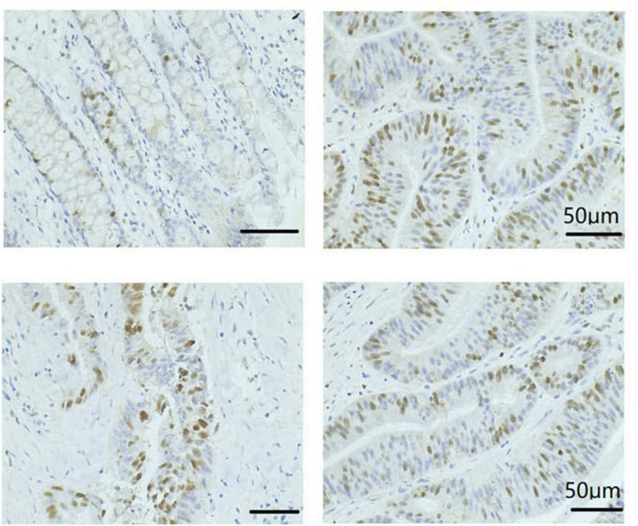
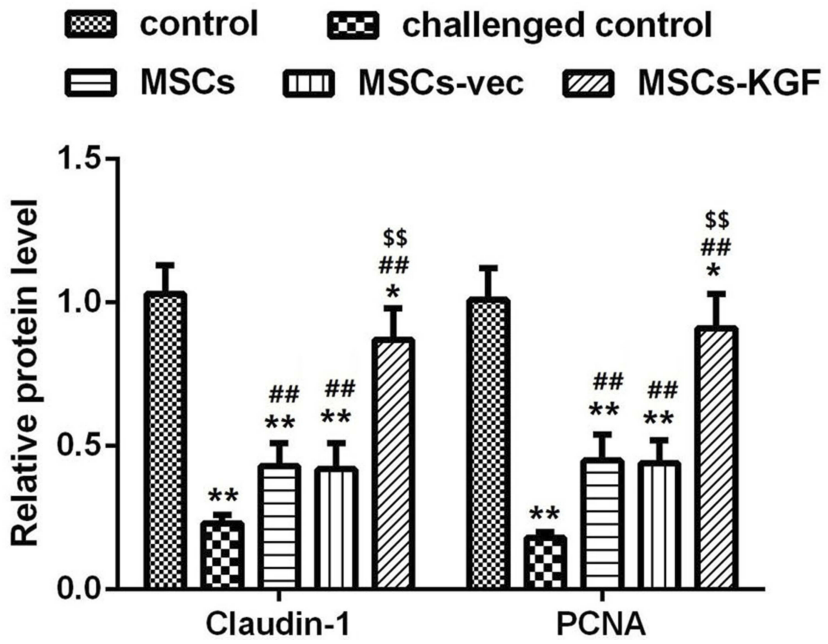

Figure 6 The expression of Claudin-I and PCNA in rat intestinal tissues. (A) Immunohistochemistry images from the intestinal tissues of rats for Claudin-I and PCNA Scale bar $=50 \mu \mathrm{m}$. (B) The expression of Claudin-I and PCNA was detected by Western blot assay. $\mathrm{n}=10$. Data shown are mean \pm SD. $* \mathrm{p}<0.05$, $* * \mathrm{p}<0.0 \mathrm{I}$ vs control group; $\#^{\#}<0.01$ vs Model group; ${ }^{\$} \mathrm{P}<0.01$ vs MSCs group.

Abbreviations: MSCs, mesenchymal stem cells; KGF, keratinocyte growth factor.

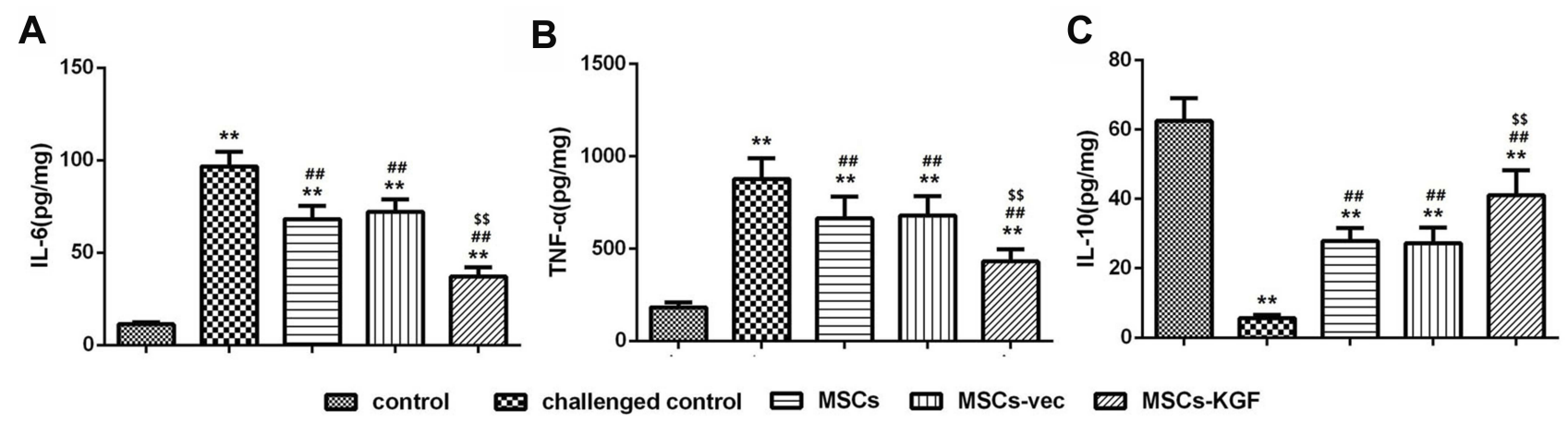

Figure 7 Comparison of TNF- $\alpha$, IL-6 and IL-10 levels in rat intestinal tissue. The contents of TNF- $\boldsymbol{\alpha}$ (A), IL-6 (B) and IL-I0 (C) in rat intestinal tissues were detected by ELISA. $n=10$. Data shown are mean \pm SD. ${ }^{* *} p<0.01$ vs control group; ${ }^{\# \#} \mathrm{p}<0.01$ vs Model group; ${ }^{\$ \$} \mathrm{p}<0.01$ vs MSCs group. Abbreviations: MSCs, mesenchymal stem cells; KGF, keratinocyte growth factor.

colonization of MSCs in colon tissue of UC rats, and these MSCs were also modified with adenovirus. We also found that the colonic morphology and pathological damage of
UC rats were improved to varying degrees after MSCs intervention, which to a certain extent explained the effect of MSCs intervention on colon tissue injury of UC rats. 
A

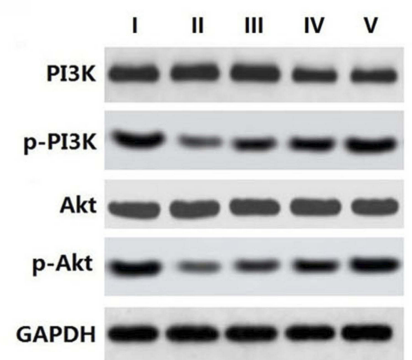

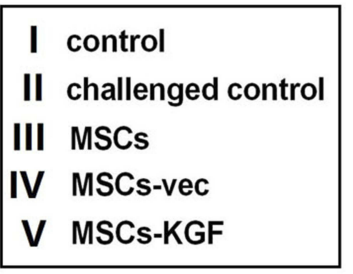

C
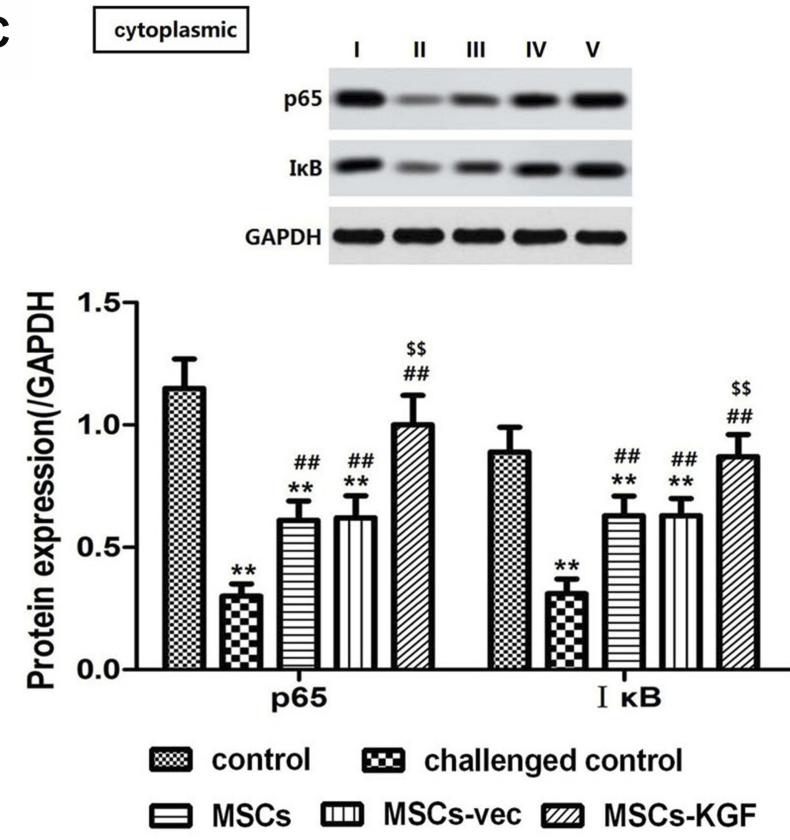

B
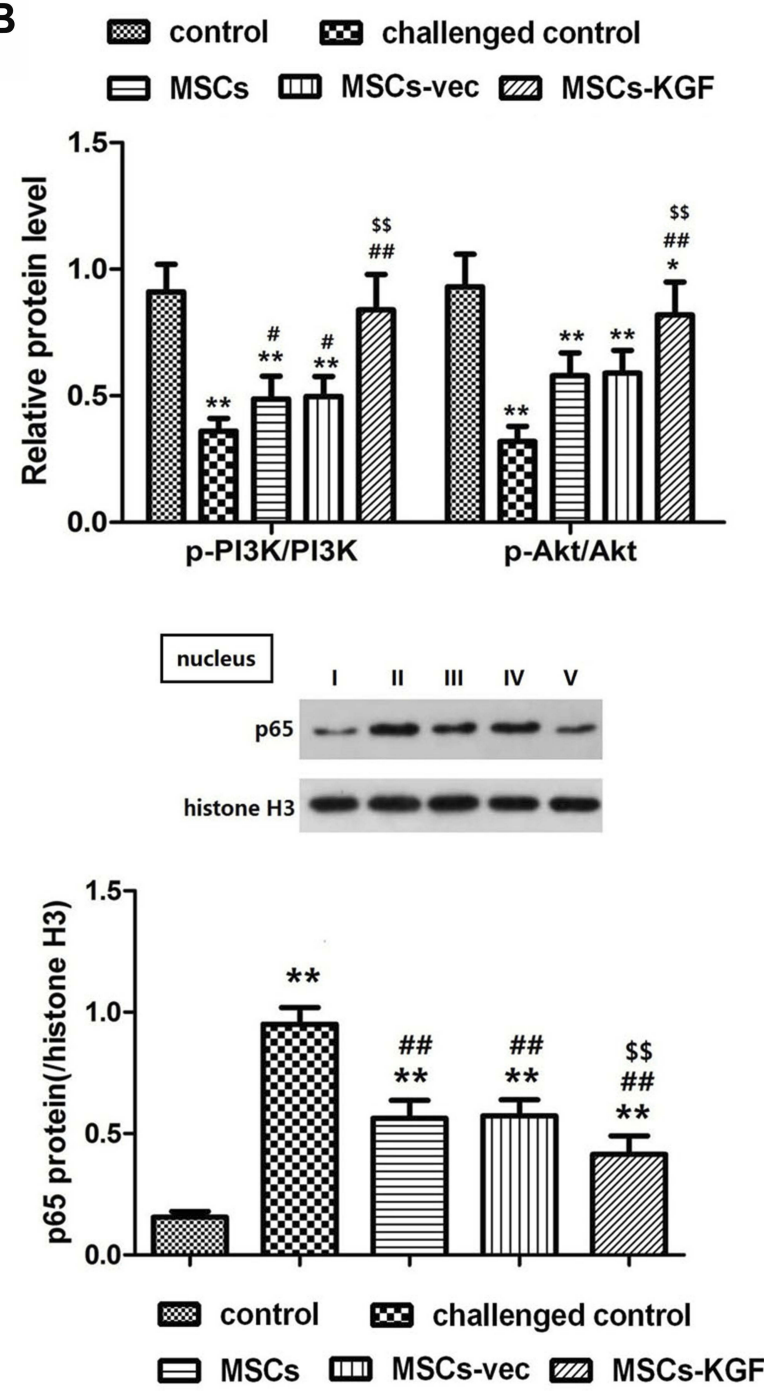

Figure 8 Effect of MSCs-KGF treatment on PI3K/Akt signaling pathway and NF-KB pathway in intestinal tissues of UC rats. (A) Western blot showing the relative expression levels of PI3K/Akt pathway-related proteins in rats treated with or without MSCs. (B) Quantitative analysis of the ratio of phosphorylated-PI3K(p-PI3K) and p-Akt proteins to total PI3K (PI3K) and total Akt (Akt). (C) Western blot analysis of cytoplasmic and nuclear NF-kB p65. GAPDH and histone H3 were used for normalization for cytoplasmic and nuclear protein, respectively. $n=10$. Data shown are mean $\pm S D$. ${ }^{* *} p<0.01$ vs control group; ${ }^{\#}<<0.05,{ }^{\# \#} p<0.01$ vs $M o d e l$ group; ${ }^{\$ \$} p<0.01$ vs MSCs group.

Abbreviations: UC, ulcerative colitis; MSCs, mesenchymal stem cells; KGF, keratinocyte growth factor.

However, we also found that MSCs can cause enormous hyperplasia in colon tissue, which may be related to the strong proliferative effect of MSCs.

Genetically engineered MSCs have become the new direction of stem cell transplantation research. Genetic modification can inhibit the apoptosis of MSCs and increase cell viability, ${ }^{23,24}$ and can further enhance the success rate of transplantation by enhancing the immunosuppressive effect of MSCs. ${ }^{6}$ Recent studies have confirmed that MSCs are ideal cell expression vectors for the KGF gene. ${ }^{11} \mathrm{Ha}$ et $\mathrm{al}^{24}$ found that KGF/HIF-1 modified MSCs can promote spinal cord injury (SCI) repair in rats. We also found that KGF can promote the entry of MSCs into TNBSinduced intestinal tissue. Particularly, we found that MSCsKGF has a better protective effect on intestinal mucosa of UC rats than MSCs and MSCs-vec alone, which may be related to the repair effects of KGF. KGF belongs to the FGFs family that has the function of promoting the repair of damaged tissues. It is considered to be a mediator of mesenchymal-epithelial interaction, which can accelerate the proliferation and differentiation of epithelial cells by regulating the interaction between MSCs and epithelial 
cells. $^{25}$ Administration of KGF visibly reduced intestinal epithelial crypt damage and enhanced intestinal mucosal tolerance. ${ }^{26}$ In a mouse model of total parenteral nutrition (TPN), administration of KGF significantly increased intestinal mucosal barrier function. ${ }^{27}$ Miceli et $\mathrm{al}^{28}$ found in the DSS-induced ulcer model that KGF can almost completely restore normal cell structure on the intestinal surface. We also found that MSCs-KGF can promote the proliferation of intestinal mucosal epithelial cells to reduce the decrease of tight junction protein expression induced by TNBS-induced colitis to protect intestinal mucosal epithelial cells. KGF also plays an important role in the inflammatory immune response. ${ }^{29}$ Studies have shown that KGF downregulates macrophage function by stimulating the release of epithelial cell-derived mediators. ${ }^{30} \mathrm{KGF}$ reduces transcription of a variety of interferon-induced genes, suggesting that it may attenuate the response of epithelial cells to inflammatory mediators. ${ }^{31}$ In dextran sulfate sodium (DSS)-induced colon injury model, KGF knockout mice have severe intestinal mucosal damage and slower recovery than wild-type mice, and KGF knockout mice are more prone to colonic inflammation and tissue repair delay. ${ }^{32}$ Inhibiting colon inflammation can reduce the sensitivity of colitis-related colorectal cancer, and anti-inflammatory technology may become an important means of preventing and/or treating inflammatory bowel diseases. ${ }^{33}$ We also found that MSCs-KGF treatment can improve colon inflammation in UC rats to a certain extent by inhibiting the secretion of inflammatory factors. The PI3K/Akt signaling pathway is an important pathway that is found to be involved in the repair process of damage during various injury repair processes. Zhang et $\mathrm{al}^{34}$ found that activation of the PI3K/Akt pathway inhibits LPS-induced monocyte activation and acute inflammatory responses in vivo and in vitro. Chang et $\mathrm{al}^{35}$ revealed that KGF can enhance Akt phosphorylation in breast cancer cells and can be blocked by PI3K/Akt pathway inhibitor LY. KGF can also activate the PI3K pathway by phosphorylating and activating P70S6k to promote the proliferation of corneal epithelial cells to participate in corneal wound repair. ${ }^{36}$ Portnon et al ${ }^{37}$ found in the culture of primary rat alveolar type II cells that KGF can activate the PI3K/Akt pathway to promote alveolar epithelial proliferation. Ray et $\mathrm{al}^{38}$ demonstrated in a hyperbaric oxygen-induced lung injury model that KGF maintains alveolar integrity by inducing Akt phosphorylation. Bao et $\mathrm{al}^{39}$ showed that KGF-activated Akt is PI3Kdependent, which protects the lung epithelium by activating the PI3K/Akt signaling pathway to inhibit apoptosis, which may serve as a therapeutic target for maintaining epithelial integrity during inflammation. We also found that MSCsKGF promotes phosphorylation of PI3K/Akt pathwayassociated proteins. We hypothesized that the promotion of KGF on the proliferation of intestinal mucosal epithelial cells may be related to the activation of PI3K/Akt signaling pathway. Furthermore, we found that the effect of MSCs or MSCs-vec alone on the PI3K/Akt signaling pathway is not obvious, which may be due to the fact that KGF secreted by MSCs through the paracrine pathway is not sufficient to activate the $\mathrm{PI} 3 \mathrm{~K} / \mathrm{Akt}$ pathway.

Activation of $\mathrm{NF}-\kappa \mathrm{B}$ is a common pathway for the mechanisms of action of many inflammatory mediators. ${ }^{40}$ Activated NF- $\mathrm{KB}$ is transferred into the nucleus to initiate or regulate the transcription of early inflammatory genes to produce large amounts of inflammatory factors including TNF- $\alpha$, IL-6. In turn, inflammatory factors can also phosphorylate IKK by activating NF- $\mathrm{BB}$-inducible kinase (NIK). The activated IKK then phosphorylates I $\mathrm{B}$, which in turn is degraded by proteases, allowing NF- $\kappa B$ to be released and activated to further amplify the inflammatory signaling cascade. Studies have confirmed that NF$\kappa \mathrm{B}$ is highly expressed in UC and induces the expression of TNF- $\alpha$, IL-1 $\beta$, IL- $6 .{ }^{41} \mathrm{NF}-\kappa \mathrm{B}$ inhibitors can significantly reduce colonic inflammatory cell infiltration, reduce TNF- $\alpha$, IL-6 and other cytokine gene expression to improve colonic inflammation. ${ }^{42} \mathrm{Li}$ et $\mathrm{al}^{43}$ demonstrated that the protective effector mechanism of KGF may be related to its blocking effect on NF- $\mathrm{BB}$ pathway. We also found that MSCs-KGF treatment can inhibit the nuclear transfer of NF- $\mathrm{BB}$. We hypothesized that the enhanced effect of KGF gene modification on the antiinflammatory effects of MSCs may be related to its downregulation of $\mathrm{NF}-\kappa \mathrm{B}$ activation.

\section{Conclusion}

In summary, KGF gene modification can enhance the repair of MSCs on colonic tissue damage in UC rats. The enhancement of MSCs by KGF may be related to the regulation of intestinal epithelial cell proliferation and colonic inflammatory response, which may be achieved by activating PI3K/ Akt pathway and inhibiting NF- $\mathrm{B}$ activation. Taken together, our findings may provide insights into the application of stem cell transplantation, and genetically modified stem cells obtained based on genetic engineering may provide new ideas for the treatment of UC. 


\section{Disclosure}

The authors report no conflicts of interest in this work.

\section{References}

1. Pei L-Y, Ke Y-S, Zhao -H-H, et al. Role of colonic microbiota in the pathogenesis of ulcerative colitis. BMC Gastroenterol. 2019;19:10. doi:10.1186/s12876-019-0930-3

2. Werner $T$, Haller D. Intestinal epithelial cell signalling and chronic inflammation: from the proteome to specific molecular mechanisms. Mutat Res. 2007;622(1-2):42-57. doi:10.1016/j.mrfmmm.2007.05.010

3. Prockop DJ, Oh JY. Mesenchymal stem/stromal cells (MSCs): role as guardians of inflammation. Mol Ther. 2012;20(1):14-20. doi:10. 1038/mt.2011.211

4. Calvo-Asensio I, Dillon ET, Lowndes NF, Ceredig R. The transcription factor Hif-1 enhances the radio-resistance of mouse MSCs. Front Physiol. 2018;9:439. doi:10.3389/fphys.2018.00439

5. Kumagai G, Tsoulfas P, Toh S, McNiece I, Bramlett HM, Dietrich WD. Genetically modified mesenchymal stem cells (MSCs) promote axonal regeneration and prevent hypersensitivity after spinal cord injury. Exp Neurol. 2013;248:369-380. doi:10.1016/j.expneurol.2013.06.028

6. Nan Z, Fan H, Tang Q, et al. Dual expression of CXCR4 and IL-35 enhances the therapeutic effects of BMSCs on TNBS-induced colitis rats through expansion of tregs and suppression of Th17 cells. Biochem Biophys Res Commun. 2018;499(4):727-734. doi:10.1016/ j.bbrc.2018.03.043

7. Yamamoto-Fukuda T, Akiyama N, Takahashi M, Kojima $\mathrm{H}$. Keratinocyte Growth Factor (KGF) modulates epidermal progenitor cell kinetics through activation of p63 in middle ear cholesteatoma. J Assoc Res Otolaryngol. 2018;19:223-241. doi:10.1007/s10162018-0662-z

8. Zoller M, Rajasagi M, Vitacolonna M, Luft T. Thymus repopulation after allogeneic reconstitution in hematological malignancies. Exp Hematol. 2007;35(12):1891-1905. doi:10.1016/j.exphem.2007.08.005

9. Yang K, Yin J, Sheng B, et al. AhRE2F1KGFR signaling is involved in KGFinduced intestinal epithelial cell proliferation. Mol Med Rep. 2017;15(5):3019-3026. doi:10.3892/mmr.2017.6368

10. Li H, Xu Y, Fu Q, Li C. Effects of multiple agents on epithelial differentiation of rabbit adipose-derived stem cells in 3D culture. Tissue Eng A. 2012;18(17-18):1760-1770. doi:10.1089/ten.tea.2011. 0424

11. Yao L, Liu CJ, Luo Q, et al. Protection against hyperoxia-induced lung fibrosis by KGF-induced MSCs mobilization in neonatal rats. Pediatr Transplant. 2013;17(7):676-682. doi:10.1111/petr.12133

12. Yang Y, Guo W, Mai Z, Fan H, Zhao Y. Effects of KGF, HIF-1 and their interplay in repair of spinal cord injuries in rats. Med Pharm $J$ Clin PLA. 2015;27(10):20-24.

13. Cooper HS, Murthy SN, Shah RS, Sedergran DJ. Clinicopathologic study of dextran sulfate sodium experimental murine colitis. Lab Invest. 1993;69(2):238-249.

14. Paiotti AP, Ribeiro DA, Silva RM, et al. Effect of COX-2 inhibitor lumiracoxib and the TNF-alpha antagonist etanercept on TNBS-induced colitis in wistar rats. J Mol Histol. 2012;43 (3):307-317. doi:10.1007/s10735-012-9400-8

15. Kostic M, Djakovic L, Sujic R, Godman B, Jankovic SM. inflammatory bowel diseases (crohn $\mathrm{s}$ disease and ulcerative colitis): cost of treatment in serbia and the implications. Appl Health Econ Health Policy. 2017;15(1):85-93. doi:10.1007/s40258-016-0272-z

16. Itoi M, Tsukamoto N, Yoshida H, Amagai T. Mesenchymal cells are required for functional development of thymic epithelial cells. Int Immunol. 2007;19(8):953-964. doi:10.1093/intimm/dxm060

17. Jin C, Zhu M. RelB intrinsically regulates the development and function of medullary thymic epithelial cells. Sci China. 2018;61 (9):43-52.
18. Lo Sicco C, Reverberi D, Balbi C, et al. Mesenchymal stem cell-derived extracellular vesicles as mediators of anti-inflammatory effects: endorsement of macrophage polarization. Stem Cells Transl Med. 2017;6(3):1018-1028. doi:10.1002/sctm.16-0363

19. Zhang X, Shi Y, Shou Z. Repair effect of matrine and bone marrow mesenchymal stem cells on colon tissue of ulcerative colitis rats. J Immunol. 2013;29(10):829-834.

20. Xiong X, Wu K, Fei S, Wang S, Han H. Influence and mechanism research of MSCs on rat with ulcerative colitis. Chin J Clin. 2013;28 (7):276-282.

21. Forbes GM, Sturm MJ, Leong RW, et al. A Phase 2 study of allogeneic mesenchymal stromal cells for luminal Crohn's disease refractory to biologic therapy. Clin Gastroenterol Hepatol. 2014;12 (1):64-71. doi:10.1016/j.cgh.2013.06.021

22. He X, Chen Z, Zhang L, et al. Efficacy and oncological safety of bone marrow mesenchymal stem cell transplantation for colitis in inflammatory bowel disease models in mice. Chin J Tissue Eng Res. 2014;18(23):3696-3701.

23. $\mathrm{Ni} \mathrm{X}, \mathrm{Ou} \mathrm{C}, \mathrm{Guo} J$, et al. Lentiviral vector-mediated co-overexpression of VEGF and Bcl-2 improves mesenchymal stem cell survival and enhances paracrine effects in vitro. Int $J \mathrm{Mol} \mathrm{Med}$. 2017;40(2):418-426. doi:10.3892/ijmm.2017.3019

24. Ha X, Deng Z, Xiao N, Zhu X, Li J. Effect of rhodiala rosea combined with KGF/HIF-1 in repair of spinal cord injuries mediated by bone marrow mesenchymal stem cells under hypoxia condition in rats. Med Pharm J Clin PLA. 2015;27(10):15-19.

25. LaFemina MJ, Rokkam D, Chandrasena A, et al. Keratinocyte growth factor enhances barrier function without altering claudin expression in primary alveolar epithelial cells. Am J Physiol Lung Cell Mol Physiol. 2010;299(6):L724-L734. doi:10.1152/ajplung. 00233.2010

26. Farrell CL, Rex KL, Chen JN, et al. The effects of keratinocyte growth factor in preclinical models of mucositis. Cell Prolif. 2002;35 Suppl 1:78-85. doi:10.1046/j.1365-2184.35.s1.8.x

27. Yang H, Wildhaber B, Tazuke Y, Teitelbaum DH. Keratinocyte growth factor stimulates the recovery of epithelial structure and function in a mouse model of total parenteral nutrition. JPEN $J$ Parenter Enteral Nutr. 2002;26(6):333-340; discussion 340-331. doi:10.1177/0148607102026006333

28. Miceli R, Hubert M, Santiago G, et al. Efficacy of keratinocyte growth factor-2 in dextran sulfate sodium-induced murine colitis. J Pharmacol Exp Ther. 1999;290(1):464-471.

29. Xu JF, Qu JM, He LX, Ou ZL. Impaired upregulation of keratinocyte growth factor in injured lungs induced by Pseudomonas aeruginosa in immunosuppressed rats. Chin Med J. 2006;119(17):1421-1429. doi:10.1097/00029330-200609010-00003

30. Ware LB, Matthay MA. Keratinocyte and hepatocyte growth factors in the lung: roles in lung development, inflammation, and repair. $\mathrm{Am}$ $J$ Physiol Lung Cell Mol Physiol. 2002;282(5):L924-L940. doi:10.1152/ajplung.00439.2001

31. Fehrenbach H, Fehrenbach A, Pan T, Kasper M, Mason RJ. Keratinocyte growth factor-induced proliferation of rat airway epithelium is restricted to Clara cells in vivo. Eur Respir J. 2002;20 (5):1185-1197. doi:10.1183/09031936.02.00022702

32. Chen Y, Chou K, Fuchs E, Havran WL, Boismenu R. Protection of the intestinal mucosa by intraepithelial gamma delta T cells. Proc Natl Acad Sci U S A. 2002;99(22):14338-14343.

33. Kesharwani SS, Ahmad R, Bakkari MA, et al. Site-directed non-covalent polymer-drug complexes for inflammatory bowel disease (IBD): formulation development, characterization and pharmacological evaluation. $J$ Control Release. 2018;290:165-179. doi:10.1016/j.jconrel.2018.08.004

34. Zhang WJ, Wei H, Hagen T, Frei B. Alpha-lipoic acid attenuates LPS-induced inflammatory responses by activating the phosphoinositide 3-kinase/Akt signaling pathway. Proc Natl Acad Sci U S A. 2007;104(10):4077-4082. doi:10.1073/pnas.0700305104 
35. Chang HL, Sugimoto Y, Liu S, et al. Keratinocyte growth factor (KGF) regulates estrogen receptor-alpha (ER-alpha) expression and cell apoptosis via phosphatidylinositol 3-kinase (PI3K)/Akt pathway in human breast cancer cells. Anticancer Res. 2009;29(8):3195-3205.

36. Chandrasekher G, Kakazu AH, Bazan HE. HGF- and KGF-induced activation of PI-3K/p70 s6 kinase pathway in corneal epithelial cells: its relevance in wound healing. Exp Eye Res. 2001;73(2):191-202. doi:10.1006/exer.2001.1026

37. Portnoy J, Curran-Everett D, Mason RJ. Keratinocyte growth factor stimulates alveolar type II cell proliferation through the extracellular signal-regulated kinase and phosphatidylinositol 3-OH kinase pathways Am J Respir Cell Mol Biol. 2004;30(6):901-907. doi:10.1165/rcmb.200304060C

38. Ray P, Devaux Y, Stolz DB, et al. Inducible expression of keratinocyte growth factor (KGF) in mice inhibits lung epithelial cell death induced by hyperoxia. Proc Natl Acad Sci U S A. 2003;100 (10):6098-6103. doi:10.1073/pnas.1031851100

39. Bao S, Wang Y, Sweeney P, et al. Keratinocyte growth factor induces Akt kinase activity and inhibits Fas-mediated apoptosis in A549 lung epithelial cells. Am J Physiol Lung Cell Mol Physiol. 2005;288(1): L36-L42. doi:10.1152/ajplung.00309.2003
40. Liu D, Huo X, Gao L, Zhang J, Ni H, Cao L. NF-kappaB and Nrf2 pathways contribute to the protective effect of Licochalcone A on dextran sulphate sodium-induced ulcerative colitis in mice. Biomed Pharmacother. 2018;102:922-929. doi:10.1016/j.biopha.20 18.03 .130

41. Galvez-Llompart M, Recio MC, Garcia-Domenech R. Topological virtual screening: a way to find new compounds active in ulcerative colitis by inhibiting NF-kappaB. Mol Divers. 2011;15(4):917-926. doi:10.1007/ s11030-011-9323-4

42. Eissa N, Hussein H, Kermarrec L, et al. Chromofungin (CHR: CHGA47-66) is downregulated in persons with active ulcerative colitis and suppresses pro-inflammatory macrophage function through the inhibition of NF-kappaB signaling. Biochem Pharmacol. 2017;145:102-113. doi:10.1016/j.bcp.2017. 08.013

43. Li Y, Rinehart CA. Regulation of keratinocyte growth factor expression in human endometrium: implications for hormonal carcinogenesis. Mol Carcinog. 1998;23(4):217-225. doi:10.1002/ (ISSN)1098-2744

\section{Publish your work in this journal}

Drug Design, Development and Therapy is an international, peerreviewed open-access journal that spans the spectrum of drug design and development through to clinical applications. Clinical outcomes, patient safety, and programs for the development and effective, safe, and sustained use of medicines are a feature of the journal, which has also been accepted for indexing on PubMed Central. The manuscript management system is completely online and includes a very quick and fair peer-review system, which is all easy to use. Visit http://www. dovepress.com/testimonials.php to read real quotes from published authors. 